\title{
HEMATOPOIETIC STEM CELL TRANSPLANTATION FOR PEDIATRIC LYMPHOMAS
}

Cilmara Cristina Kuwahara MD ${ }^{1}$, Gabriele Zamperlini Neto MD ${ }^{2,3}$, Mariana Bohns Michalowski PhD ${ }^{4,5}$, Valéria Cortez Ginani MD ${ }^{6}$, Carla Nolasco Monteiro Breviglieri MD2,6

1. Hospital Pequeno Príncipe - Curitiba/PR

2. Instituto de Tratamento do Câncer Infantil (ITACI) - Instituto da Criança - Hospital das Clínicas da Universidade de São

Paulo - São Paulo/SP

3. Hospital Israelita Albert Einstein - São Paulo/SP

4. Universidade Federal do Rio Grande do Sul - Porto Alegre/SP

5. Hospital das Clínicas de Porto Alegre - Porto Alegre/RS

6. Hospital Samaritano Higienópolis - São Paulo/SP

Correspondence to: canolasco@gmail.com

\section{INTRODUCTION}

Lymphomas are the third most common cancer of childhood in Brazil, after leukemias and central nervous system tumors ${ }^{1}$.

The diagnosis and staging are based on clinical presentation, pathology findings with immunohistochemistry, molecular biology and radiological imaging. The treatment with multiagent chemotherapy or radiotherapy is defined according to the lymphoma subtype and risk stratification? ${ }^{2}$.

The prognosis of children and adolescents with non-Hodgkin lymphomas (NHL) and Hodgkin's lymphoma (HL) has markedly improved in the last decades, however relapsed or refractory disease is still associated with an inferior outcome. Aggressive chemotherapy followed by either autologous or allogenic hematopoietic stem cell transplantation (HSCT) is a salvage treatment strategy described in the literature, with particularities according to lymphoma subtype and to the available source of stem cells.

\section{NON-HODGKIN LYMPHOMA}

Pediatric NHL have excellent prognosis with conventional chemotherapy. Current protocols can achieve overall survival rates exceeding $80 \%$ for the most common subtypes (Burkitt and Diffuse Large B cell, Anaplastic Large cell and Lymphoblastic lymphomas).

The optimal approach for relapsed/refractory (R/R) patients, including the incorporation of new therapies, is unclear. Given the excellent results of firstline treatment in children and adolescents with $\mathrm{NHL}$, clinical trials for the treatment of relapses often include heterogeneous groups of patients. This fact makes it difficult to interpret and generalize the results that are obtained.

\section{MATURE B-CELL LYMPHOMAS}

Mature B-cell lymphomas (Burkitt lymphoma - BL, and diffuse large B-cell lymphoma - DLBCL) represent the largest NHL subtype with a $90 \%$ event-free survival rates according to contemporary approach$\mathrm{es}^{3}$. The R/R disease prognosis is dismal, and worse prognosis factors are the first line treatment intensity, including the addition of rituximab; elevated lactate dehydrogenase (LDH), early relapses and bone marrow involvement ${ }^{4}$.

In addition, the mature B-cell lymphoma subtype also has an impact on survival, with the DLBCL having better results when compared to BL $(52 \% \pm 10 \%$ $x 28 \pm 3 \%)^{5}$.

HSCT is considered for chemo sensitive patients, with no survival benefit for those refractory to reinduction or to first line therapy, with few anecdotal cases alive in the literature ${ }^{6-9}$.

Several rescue schemes are proposed, usually associated with the anti-CD20, such as high-risk blocks of BFM, R-ICE (rituximab, ifosfamide, carboplatin and etoposide), R-ICI/ICN (rituximab, ifosfamide, carboplatin, idarubicin/mitoxantrone, paclitaxel) or R-VICI (rituximab, vincristine, idarubicin, ifosfamide, carboplatin and dexamethasone). Unfortunately, progressive disease occurs in about $50 \%$ of cases during reinduction, 
with better results found with the $\mathrm{R}-\mathrm{VICl}$ schema (up to 20 improvement in progression free survival) 9 .

It is well known that those salvage regimens are associated with severe hematological toxicities and risk of failure in mobilization and stem cell harvest. The allogeneic HSCT is an alternative to the autologous HSCT with similar outcomes and, therefore, better results than conventional chemotherapy without $\mathrm{HSCT}^{8,10-13}$. Most of the retrospective studies include long periods and small number of patients, not allowing conclusions regarding the Graft versus Lymphoma (GVL) effect and the potential survival advantaged associated with the allogeneic HSCT.

Although there are no prospective randomized studies exploring the best HSCT modality, there is a tendency to perform autologous transplants in DLBCL, while in BL both modalities (allogeneic and autologous) overlap, with similar results $(46 \pm 5 \% \times 44 \pm 6 \%)^{5}$.

Different conditioning regimens are described for autologous transplants, mainly containing carmustine (e.g. BEAM). Since carmustine is no longer available in Brazil, busulfan-based regimens are alternatives.

For allogeneic HSCT, myeloablative regimens with Total Body Irradiation (TBI) and busulfan and Burkitt's reduced intensity conditioning including rituximab, fludarabine, thiotepa, carboplatin, mitoxantrone and paclitaxel are suggested $d^{5,3}$.

\section{LYMPHOBLASTIC LYMPHOMAS}

Lymphoblastic lymphomas (LL) are the second most frequent subtype of $\mathrm{NHL}$ in childhood and about $10 \%$ of patients experience relapses or progression on current protocols ${ }^{14}$. For those patients, long-term remissions are not sustained with chemotherapy alone and bone marrow transplantation is usually recommended in patients in complete remis$\operatorname{sion}^{15,16}$. Data from the CIBMTR showed better 5-year event-free survival in patients undergoing allogeneic HSCT (40\%) when compared to autologous bone marrow transplantation $(4 \%)^{12}$. Thus, allogeneic HSCT based on acute lymphoblastic leukemia (ALL) principles is the standard of care for $R / R$ LL.

\section{LARGE ANAPLASTIC CELL LYMPHOMAS}

Childhood large anaplastic cell lymphomas (ALCL) represent 10 to $15 \%$ of pediatric NHL lymphomas with survival rates ranging from 70 to $85 \%$ in different cooperative trials ${ }^{17-19}$.
Approximately 25 to $35 \%$ of patients progress to relapsed or refractory disease. In these cases, there is no consensus on the best treatment strategy. Unlike the other NHL subgroups, salvage therapy is effective on $\mathrm{R} / \mathrm{R}$ ALCL and response rates around $80 \%$ are achieved ${ }^{20,21}$.

Bone marrow transplantation is a curative alternative for those patients and both autologous and allogeneic HSCT are addressed in the literature. Risk factors such as early relapses ( $<12$ months from initial diagnosis), progression during first-line therapy, involvement of bone marrow and Central Nervous System at relapse and CD3 expression on the primary tumor are associated with unfavorable outcomes in retrospective series $^{21,22}$. Results from the CIBMTR, the Berlin-Frankfurt-Muenster group (BFM) and the Japanese group report a 5-year event-free survival of 35\%, 59\% and $38 \%$, respectively ${ }^{12,21,23}$. Patients in CR at the time of autologous transplantation had better results when compared to patients with active disease ${ }^{23}$.

A recent prospective trial conducted by the European group showed that late relapses could be treated with vinblastine as a single agent and that high risk disease had $65 \%$ 5-year EFS following allogeneic HSCT. The autologous transplantation arm, initially planned for patients in the intermediate risk group (CD3 negative with relapse $<1$ year and who had already received vinblastine) was held after inferior outcomes results were described when compared to the allogeneic HSCT group (EFS $44 \% \pm 9 \%$ ), suggesting that early relapse disease should be consolidated with allogeneic transplantation ${ }^{24}$.

Allogeneic HSCT with myeloablative conditionings (with TBI or busulfan) and reduced intensity are described in the literature with EFS ranging from 50 to $75 \%{ }^{23-26}$.

In the recent European prospective trial published by Knorr et al, the conditioning regimen adopted for $56 \mathrm{ALCL}$ relapsed patients consisted of TBI 12Gy (substituted by bussulfan in patients younger than 24months), thiotepa and etoposide.

The incorporation of new drugs, such as brentuximab vedotin and crizotinib, are explored by some cooperative groups, however the optimal approach, whether associated or not with HSCT, has not been properly established so far.

\section{POST-TRANSPLANT MAINTENANCE THERAPY}

There are few studies regarding the use of post-HSCT maintenance in NHL in the pediatric group. Tavern JA 
et al published a systematic review in patients older than 18 years and no benefit was observed with the addition of rituximab in DLBCL. Check point inhibitors are promising options for future trials ${ }^{27,28}$. The use of Brentuximab, Crizotinib (ALK inhibitor) and Nivolumab in R/R ALCL, both as a brige to HSCT and maintanance after high dose chemotherapy have been studied, however with no conclusive results so far $^{29}$.

\section{SUMMARY OF TREATMENT RECOMMENDATIONS FOR NHL HISTOLOGICAL SUBTYPES}

In R/R NHL it is important to maintain high dose-intense treatment, avoid treatment delays and consider treatment continuation prior to full hematological recovery, especially in mature B-cell lymphomas. There is limited or no role for irradiation and surgery in these scenarios. Achieve CR prior to HSCT is associated with better survival, and early taper of immunosuppression after allogeneic HSCT may allow lower relapse rates.

Specific recommendations for each NHL subtypes are described in table 1. There are unique clinical scenarios not covered by these recommendations that may require individualized decisions.

\section{HODGKIN LYMPHOMA}

Hodgkin's lymphomas in children and adolescents, likewise pediatric NHL, have excellent survival with conventional chemotherapy associated or not with radiotherapy. Even high-risk patients at diagnosis have a good chance of cure with standard treatment and, therefore, autologous HSCT (ASCT) is not recommended as frontline therapy in pediatric $\mathrm{HL}$, but it is considered for relapsed or primarily refractory diseases $(R / R)^{30-32}$.

Some risk factors have been associated with inferior outcomes for R/R patients, such as bulky disease at diagnosis, B-symptoms, extra nodal disease, first-line chemo resistance, relapses within 12 months from diagnosis, advanced stage disease at relapsed and number of previous treatment regimens. The prognostic marker that seems to be more important is the result of the fluro-deoxy-glucose positron emission tomography (FDG PET) pre HSCT with a 10-year EFS of $31 \%$ (PET positive) versus $75 \%$ (PET negative) ${ }^{33-35}$.

Recently, a guideline was published from the EuroNet Paediatric Hodgkin Lymphoma Group ${ }^{36}$. According to this guideline the risk stratification at the point of relapse identifies 3 groups: low, standard and high risk groups (table 2). The low and standard risk are based on assessment of pre-salvage risk factors, and the high risk is based on response of treatment i.e., the failure to achieve a negative FDG-PET after 2 lines of salvage standard dose chemotherapy (SDCT).

The European guideline proposed that the low-risk group could be treated with SDCT plus radiotherapy consolidation only, the standard risk group could be treated with SDCT plus high dose chemotherapy and autologous stem cell transplant (HDCT/ASCT) consolidation and the high-risk group is eligible for conventional HDCT/ ASCT plus additional treatments pre and/or post HDCT/ ASCT or experimental strategies. The aim of salvage chemotherapy is to achieve a complete metabolic remission (CMR) defined as Deauville $1-3$ or qPET $<1.3$ (in the EuroNet group the semi-quantitative "qPET" method is widely used which is a quantitative extension of the Deauville scale; Deauville 4 and 5 are respectively equivalent to qPET values of 1.3 and 2.0 and a positive PET scan is a qPET value $>1.3$ ).

Myeloablative chemotherapy with ASCT is the recommended approach for patients who develop refractory disease during therapy or relapsed disease within 1 year after completing therapy. In addition, this approach is also recommended for those who recur with extensive disease after the first year of completing therapy or for those who recur after initial therapy that included intensive (alkylating agents and anthracyclines) multiagent chemotherapy and radiation therapy ${ }^{2}$.

Most of the conditioning regimens for ASCT include carmustine, such as BEAM (carmustine, etoposide, cytarabine and melphalan) or CBV (carmustine, etoposide and cyclophosphamide). However, as carmustine was discontinued in Brazil and in several countries as previously mentioned, there was a need to explore different regimes such as: melphalan/ etoposide; busulfan/ melphalan; gemcitabine/ busulfan/ melphalan; and alternatives to the carmustine, including bendamustine (Benda-EAM), fotemustine, lomustine (LEAM), mitoxantrone and thiotepa. There are no studies comparing the efficacy among all different conditioning regimens and therefore, there is no standard conditioning in the pediatric literature. The optimal regimen should be based on clinical status, known efficacy of previous drugs utilized, tumor localization, financial cost and regulatory approval by local authorities.

Some strategies have been adopted to improve results for high-risk R/R candidates to bone marrow 
transplantation, including better salvage treatment, alternative transplant modalities, e.g. TANDEM, and post transplantation maintanence therapy.

Radiation is a well-known effective therapy for $\mathrm{HL}$, however the site of irradiation and potential toxicity should be considered when it is indicated. The ideal radiation timing is controversial, although many authors recommend radiotherapy after the autologous $\mathrm{HSCT}^{36}$.

Brentuximab vedotin (BV) (anti-CD30) can be used for salvage treatment in $R / R$ patients, as a bridge to transplantation ${ }^{37}$, and as a post transplant maintenance therapy ${ }^{38}$. In a randomized study, a 1year post-transplant maintenance with BV was associated with better disease-free survival (DFS), although no impact on overall survival was observed. Similarly, checkpoint inhibitors (PD-1) are also explored for pediatric high-risk patients, with promising results $36,37,39$.

Immunotherapy remains an experimental treatment in $\mathrm{R} / \mathrm{R} \mathrm{HL}$ in children and young people and there are clinical trials in progress. It may be considered in high risk patients that were refractory to SDCT salvage regimens. Single agent Nivolumab achieves a low $C R$ rate and combination of Brentuximab plus Nivolumab looks more promising ${ }^{36}$. Pembrolizumab was well tolerated in pediatric patients and showed encouraging antitumour activity in children with relapsed or refractory Hodgkin lymphoma, similar to the experience described in adult ${ }^{40,41}$.

TANDEM transplantation is an alternative for patients considered at high-risk for relapses after autologous
HSCT. This approach consists of a myeloablative autologous HSCT followed by a non myeloablative conditioning allogeneic transplant ${ }^{42}$.

Allogeneic HSCT can be considered for post autologous HSCT relapses, as well as in cases of failure to harvest stem cells from the bone marrow or the peripheral blood and in cases of several relapses. The conditioning regimens are either myeloablative (MAC) or reduced intensity (RIC), with an expected graft versus lymphoma effect to reduce the risk of relapse. The overall survival is comparable in both MAC and RIC approaches, with relapses more like to occur after a RIC regimen, whereas toxicity is more common following MAC strategy. The choice between RIC and MAC should consider the patient clinical status, previous treatments and the perspective of adjuvant therapy ${ }^{30}$.

As HLA identical related or unrelated donors are only available for a subset of patients, alternative donors often need to be found. Recently, the use of T-cell-replete haploidentical stem cell transplantation (haplo-HSCT) with post-infusion cyclophosphamide (PT-Cy) in advanced hematological malignancies showed a good toxicity profile. It has been observed that haplo- HSCT act effectively against HL cells (immunological effect) and is a good choice in the treatment of poor prognosis $\mathrm{HL}$ in patients who do not find a HLA compatible donor ${ }^{43}$. Comparative studies demonstrated that Allogeneic HSCT from full-matched and haploidentical donors have similar outcomes, there is a reduced relapse rate and better overall survival with post-Cyclophosphamide haplo-HSCT ${ }^{44-46}$. 
TABLE 1. Consensus recommendation for $\mathrm{NHL}$

\begin{tabular}{|c|c|c|c|}
\hline Subtype & 2nd line treatment & HSCT & Conditioning regimen \\
\hline BL & $\begin{array}{l}\text { 2-3 courses R-ICE or } \\
\text { R-VICl }\end{array}$ & Autologous or allogeneic & $\begin{array}{l}\text { Autologous - Busulfan based regimen } \\
\text { Allogeneic - TBI or busulfan based, Burkitt-specific RIC }\end{array}$ \\
\hline DLBCL & $2-3$ courses $\mathrm{R}-\mathrm{ICE}$ & Autologous & Busulfan based regimen \\
\hline LL & $\begin{array}{l}\text { Intense treatment } \\
\text { courses analogue to } \\
\text { high-risk ALL or relapsed } \\
\text { ALL protocols }\end{array}$ & Allogeneic & TBI based regimen \\
\hline $\mathrm{ALCL}$ & Vinblastine, ICE & $\begin{array}{l}\text { Allogeneic for high-risk } \\
\text { patients } \\
\text { Vinblastine if low risk, } \\
\text { without HSCT }\end{array}$ & TBI or busulfan based regimen \\
\hline
\end{tabular}

Adapted from Burkhardt B, $2021^{5}$

TABLE 2. Risk Stratification for First Relapsed and Refractory Classical Hodgkin Lymphoma in Children and Young People

\begin{tabular}{|c|c|}
\hline Low Risk Group & $\begin{array}{l}\text { 1.Early relapse after a maximum } 4 \text { cycles of first line chemotherapy. } \\
\text { or } \\
\begin{array}{r}\text { 2. Late relapse after a maximum of } 6 \text { cycles of first line chemotherapy. } \\
\text { And ALL of the following } \\
\text { • Stage at relapse is I-III } \\
\text { • No prior RT or relapse only outside prior RT field } \\
\text { • No excessive RT fields required in salvage }\end{array}\end{array}$ \\
\hline Standard risk Group & $\begin{array}{l}\text { 1. Primary Progressive } \mathrm{HL} \\
\text { 2. Early Relapse after more than } 4 \text { cycles of first line chemotherapy } \\
\text { 3. Stage IV relapse } \\
\text { 4. Relapse in a prior RT field } \\
\text { 5. Relapse requiring RT in salvage that is considered as having unacceptable } \\
\text { toxicity }\end{array}$ \\
\hline High Risk Group & $\begin{array}{c}\text { High risk (HR) patients are those that fail to achieve a CMR after } 2 \text { lines of } \\
\text { SDCT on PET4. Failure to achieve a CMR prior to HDCT is associated with an } \\
\text { inferior prognosis compared to patients that achieve a negative FDG-PET scan } \\
\text { pre-HDCT/ASCT. }\end{array}$ \\
\hline
\end{tabular}

Adapted from guidelines recommendations from Euronext pediatric Hodgkin lymphoma group 
TABLE 3. Consensus recommendation for $\mathrm{HL}$

\begin{tabular}{|c|c|c|}
\hline Recommendation & Treatment options & Conditioning regimen \\
\hline $\begin{array}{l}\text { ASCT: } \\
\text { Primary refractory disease } \\
\text { Standard or high risk relapsed who } \\
\text { respond to salvage therapy }\end{array}$ & 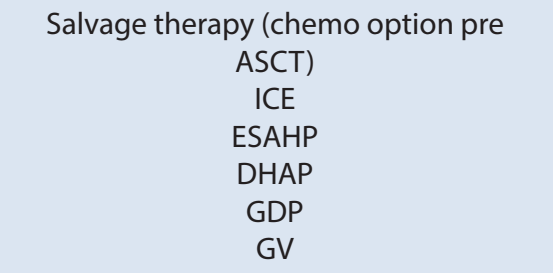 & $\begin{array}{c}\text { BEAM or CBV* } \\
\text { Bu Mel - low risk patients } \\
\text { Bu Mel Gen - high risk patients } \\
\text { LEAM } \\
\text { Be-EAM }\end{array}$ \\
\hline Post-ASCT therapy & $\begin{array}{c}\text { Radiotherapy } \\
\text { Bulky disease }(>5 \mathrm{~cm}) \text { especially if not } \\
\text { been previously irradiated) } \\
\text { Primary refractory disease } \\
\text { Persistent FDG-avid disease after salvage } \\
\text { or after ASCT } \\
\text { Brentuximab vedotin maintenance in } \\
\text { high-risk patients }\end{array}$ & \\
\hline $\begin{array}{l}\text { Allo-HCT } \\
\text { should be used for relapse after ASCT or } \\
\text { failure to mobilization }\end{array}$ & $\begin{array}{l}\text { Options for rescue: } \\
\text { Chemo protocol } \\
\text { Brentuximab }\end{array}$ & $\begin{array}{c}\text { RIC: Fludarabin based regimens: } \\
\text { - Flu Mel } \\
\text { - Flu Bu } \\
\text { MAC regimens: } \\
\text { - TBI based } \\
\text { - Bu Cy }\end{array}$ \\
\hline $\begin{array}{l}\text { Haplo } \\
\text { option for patients with Allo-HCT } \\
\text { indication, without MRD. }\end{array}$ & & $\begin{array}{c}\text { Cy Flu and TBI 2Gy } \\
\text { Post-cy }\end{array}$ \\
\hline $\begin{array}{c}\text { Tandem SCT } \\
\text { option for High Risk patients }\end{array}$ & & $\begin{array}{l}\text { ASCT: MAC } \\
\text { Allo HCT: RIC }\end{array}$ \\
\hline
\end{tabular}

*BCNU is not available at this moment in Brazil 


\section{REFERENCES:}

1. Instituto Nacional de Câncer José Alencar Gomes da Silva. Coordenação de Prevenção e Vigilância. Incidência, mortalidade e morbidade hospitalar por câncer em crianças, adolescentes e adultos jovens no Brasil: informações dos registros de câncer e do sistema de mortalidade / Instituto Nacional de Câncer José Alencar Gomes da Silva. - Rio de Janeiro: Inca, 2016

2. PDQ Pediatric Treatment Editorial Board. Childhood Hodgkin Lymphoma Treatment (PDQ ${ }^{\circledR}$ : Health Professional Version. PDQ Cancer Information Summaries [Internet]. Bethesda (MD): National Cancer Institute (US); 2002- 2021 Jun 21.

3. Minard-Colin V, Aupérin A, Pillon M, Burke GAA, Barkauskas DA, Gross TG, et al. Rituximab for high risk, mature B-cell non-hodgkin's lymphoma in children. N Engl J Med. 2020;382:22072219.

4. Cairo M, Auperin A, Perkins SL, Pinkerton R, Harrison L, Goldman S, et al. Overall survival of children and adolescents with mature $B$ cell non-Hodgkin lymphoma who had refractory or relapsed disease during or after treatment with FAB/LMB 96: A report from the FAB/LMB 96 study group. Br J Haematol. 2018;182(6):859-869.

5. Burkhardt B, Taj M, Garnier N, Minard-Colin V, Hazar V, Mellgren K, et al. Treatment and Outcome Analysis of 639 relapsed non-Hodgkin lymphoma in children and adolescentes and resulting treatment recommendations. Cancers (Basel). 2021;13(9):2075.

6. Fujita N, Mori T, Mitsui T, Inada H, Horibe K, Tsurusawa M. Lymphoma Committee of the Japanese Pediatric Leukemia/Lymphoma Study Group. The role of hematopoietic stem cell transplantation with relapsed or primary refractory childhood B-cell non-Hodgkin lymphoma and mature B-cell leukemia: a retrospective analysis of enrolled cases in Japan. Pediatr Blood Cancer. 2008;51(2):188-92.

7. Anoop P, Sankpal S, Stiller C, Tewari S, Lancaster $\mathrm{DL}$, Khabra K, et al. Outcome of childhood relapsed or refractory mature B-cell non-Hodgkin lymphoma and acute lymphoblastic leukemia. Leuk Lymphoma. 2012;53(10):1882-8.

8. Jourdain A, Auperin A, Minard-Colin V, Aladjidi N, Zsiros J, Coze C, et al. Outcome of and prognostic factors for relapse in children and adolescents with mature B-cell lymphoma and leukemia treated in three consecutive prospective "Lymphomes Malins B" protocols. A Société Française des Cancers de l'Enfant study. Haematologica. 2015;100(6):810-7.

9. Woessmann W, Zimmermann M, Meinhardt A, Müller $\mathrm{S}$, Hauch $\mathrm{H}$, Knörr $F$, et al. Progressive or relapsed Burkitt lymphoma or leukemia in children and adolescents after BFM-type first-line therapy. Blood. 2020;135(14):1124-1132.

10. Fujita N, Kobayashi R, Atsuta Y, Iwasaki F, Suzumiya J, Sasahara Y, et al. Hematopoietic stem cell transplantation in children and adolescents with relapsed or refractory B-cell non-Hodgkin lymphoma. Int J Hematol. 2019;109(4):483-490 ,

11. Rigaud C, Auperin A, Jourdain A, Haouy S, Couec $M L$, Aladjidi N, et al. Outcome of relapse in children and adolescents with B-cell non-Hodgkin lymphoma and mature acute leukemia: $A$ report from the French LMB study. Pediatr Blood Cancer. 2019;66(9):e27873.

12. Gross TG, Hale GA, He W, Camitta BM, Sanders $\mathrm{JE}$, Cairo MS, et al. Hematopoietic stem cell transplantation for refractory or recurrent non-Hodgkin lymphoma in children and adolescents. Biol Blood Marrow Transplant. 2010;16(2):223-30.

13. Burkhardt B, Pillon M, Taj M, Garnier N, Minard V, Hazar V, et al. Role of HST in children and adolescentes with refratory or relapsed NHL. British Journal of Haematology, 2018; 182(Suppl. 1):24.

14. Burkhardt B, Reiter A, Landmann E, Lang P, Lassay L, Dickerhoff R, et al. Poor Outcome for Children and Adolescents With Progressive Disease or Relapse of Lymphoblastic Lymphoma: A Report From the Berlin-Frankfurt-Muenster Group. J Clin Oncol [Internet]. 2009;27(20):3363-9.

15. Mitsui T, Mori T, Fujita N, Inada H, Horibe K, Tsurusawa M. Retrospective analysis of relapsed or primary refractory childhood lymphoblastic lymphoma in Japan. Pediatr Blood Cancer [Internet]. 2009 May 1;52(5):591-5.

16. Michaux K, Bergeron C, Gandemer V, Mechinaud F, Uyttebroeck A, Bertrand $Y$, et al. Relapsed or Refractory Lymphoblastic Lymphoma in Children: Results and Analysis of 23 Patients in the EORTC 58951 and the LMT96 Protocols. Pediatr Blood Cancer [Internet]. 2016 Jul 1;63(7):1214-21. 
17. Seidemann K, Tiemann M, Schrappe M, Yakisan E, Simonitsch I, Janka-Schaub G, et al. Shortpulse B-non-Hodgkin lymphoma-type chemotherapy is efficacious treatment for pediatric anaplastic large cell lymphoma: A report of the Berlin-Frankfurt-Münster Group Trial NHL-BFM 90. Blood. 2001;97(12):3699-706.

18. Alexander S, Kraveka JM, Weitzman S, Lowe E, Smith L, Lynch JC, et al. Advanced stage anaplastic large cell lymphoma in children and adolescents: Results of ANHL0131, a randomized phase III trial of APO versus a modified regimen with vinblastine: A report from the children's oncology group. Pediatr Blood Cancer. 2014;61(12):2236-42

19. Le Deley M-C, Rosolen A, Williams DM, Horibe $K$, Wrobel G, Attarbaschi A, et al. Vinblastine in Children and Adolescents With High-Risk Anaplastic Large-Cell Lymphoma: Results of the Randomized ALCL99-Vinblastine Trial. J Clin Oncol. 2010;28(25):3987-93

20. Brugières $L$, Pacquement $H$, Le Deley $M C$, Leverger G, Lutz P, Paillard C, et al. Single-drug vinblastine as salvage treatment for refractory or relapsed anaplastic large-cell lymphoma: A report from the french society of pediatric oncology. J Clin Oncol. 2009;27(30):5056-61.

21. Woessmann $W$, Zimmermann $M$, Lenhard M, Burkhardt B, Rossig C, Kremens B, et al. Relapsed or refractory anaplastic large-cell lymphoma in children and adolescents after Berlin-Frankfurt-Muenster (BFM)-type first-line therapy: A BFM-Group study. J Clin Oncol. 2011;29(22):3065-71.

22. Brugières $L$, Quartier $P$, Le Deley $M C$, Pacquement $\mathrm{H}$, Perel $\mathrm{Y}$, Bergeron $\mathrm{C}$, et al. Relapses of childhood anaplastic large-cell lymphoma: Treatment results in a series of 41 children - a report from the French Society of Pediatric Oncology. Ann Oncol. 2000;11(1):53-8

23. Fukano R, Mori T, Kobayashi R, Mitsui T, Fujita $\mathrm{N}$, Iwasaki F, et al. Haematopoietic stem cell transplantation for relapsed or refractory anaplastic large cell lymphoma: A study of children and adolescents in Japan. Br J Haematol. 2015;168(4):557-63.

24. Knorr $F$, Brugières $L$, Pillon $M$, Zimmermann $M$, Ruf S, Woessmann W, et al. Stem Cell Transplantation and Vinblastine monotherapy for relapsed pediatric anaplastic large cell lymphoma: results of the international, prospective ALCL-Relapse Trial. J Clin Oncol. 2020;38(34):3999-4009

25. Strullu M, Thomas C, Le Deley MC, Chevance A, Kanold J, Bertrand $Y$, et al. Hematopoietic stem cell transplantation in relapsed ALK+ anaplastic large cell lymphoma in children and adolescents: A study on behalf of the SFCE and SFGM-TC. Bone Marrow Transplant. 2015;50(6):795-801.

26. Woessmann W, Peters $C$, Lenhard $M$, Burkhardt B, Sykora KW, Dilloo D, et al. Allogeneic haematopoietic stem cell transplantation in relapsed or refractory anaplastic large cell lymphoma of children and adolescents - A Berlin-Frankfurt-Münster group report. $\mathrm{Br} J$ Haematol. 2006;133(2):176-82.

27. Kanate AS, Kumar A, Dreger $P$, Dreyling $M$, Le Gouill S, Corradini P, et al. Maintenance Therapies for Hodgkin and Non-Hodgkin Lymphomas After Autologous Transplantation: A Consensus Project of ASBMT, CIBMTR, and the Lymphoma Working Party of EBMT. JAMA Oncol. 2019;5(5):715-722

28. Taverna JA, Yun S, Jonnadula J, Saleh A, Riaz IB, Abraham I, et al. Role of Maintenance Therapy after High-Dose Chemotherapy and Autologous Hematopoietic Cell Transplantation in Aggressive Lymphomas: A Systematic Review. Biol Blood Marrow Transplant. 2016;22(7):1182-1196.

29. Prokoph N, Larose H, Lim MS, Burke GAA, Turner SD. Treatment Options for Paediatric Anaplastic Large Cell Lymphoma (ALCL): Current Standard an beyond. Cancers (Basel). 2018;10(4):99

30. Claviez A, Canals C, Dierickx D, Stein J, Badell I, Pession A, et al. Lymphoma and Pediatric Diseases Working Parties. Allogeneic hematopoietic stem cell transplantation in children and adolescents with recurrent and refractory Hodgkin lymphoma: an analysis of the European Group for Blood and Marrow Transplantation. Blood. 2009;114(10):2060-7

31. Sureda A, Canals C, Arranz R, Caballero D, Ribera JM, Brune $M$, et al. Allogeneic stem cell transplantation after reduced intensity conditioning in patients with relapsed or refractory Hodgkin's lymphoma. Results of the HDR-ALLO study - a prospective clinical trial by the Grupo Español de Linfomas/Trasplante de Médula Osea (GEL/ TAMO) and the Lymphoma Working Party of the European Group for Blood and Marrow Transplantation. Haematologica. 2012;97(2):310-7. 
32. Perales MA, Ceberio I, Armand P, Burns LJ, Chen $\mathrm{R}$, Cole PD, et al. American Society for Blood and Marrow Transplantation. Role of cytotoxic therapy with hematopoietic cell transplantation in the treatment of Hodgkin lymphoma: guidelines from the American Society for Blood and Marrow Transplantation. Biol Blood Marrow Transplant. 2015;21(6):971-83

33. Moskowitz AJ, Yahalom J, Kewalramani T, Maragulia JC, Vanak JM, Zelenetz AD, et al. Pretransplantation functional imaging predicts outcome following autologous stem cell transplantation for relapsed and refractory Hodgkin lymphoma. Blood. 2010;116(23):4934-7.

34. Shah GL, Yahalom J, Matasar MJ, Verwys SL, Goldman DA, Bantilan KS, et al. Risk factors predicting outcomes for primary refractory hodgkin lymphoma patients treated with salvage chemotherapy and autologous stem cell transplantation. Br J Haematol. 2016;175(3):440-447

35. Adams HJA, Nievelstein RAJ, Kwee TC. Systematic review and meta-analysis on the prognostic value of complete remission status at FDG-PET in Hodgkin lymphoma after completion of firstline therapy. Ann Hematol. 2016;95(1):1-9

36. Daw $S$, Hasenclever D, Mascarin M, Fernández-Teijeiro A, Balwierz W, Beishuizen A, et al. Risk and Response Adapted Treatment Guidelines for Managing First Relapsed and Refractory Classical Hodgkin Lymphoma in Children and Young People. Recommendations from the EuroNet Pediatric Hodgkin Lymphoma Group. HemaSphere, 2020;4:1.

37. Moskowitz AJ, Schöder H, Yahalom J, McCall SJ, Fox SY, Gerecitano J, et al. PET-adapted sequential salvage therapy with brentuximab vedotin followed by augmented ifosamide, carboplatin, and etoposide for patients with relapsed and refractory Hodgkin's lymphoma: a non-randomised, open-label, single-centre, phase 2 study. Lancet Oncol. 2015;16(3):284-92.

38. Sureda A, André $M$, Borchmann $P$, da Silva $M$ , Gisselbrecht C, Vassilakopoulos T, et al. Improving outcomes after autologous transplantation in relapsed/refractory Hodgkin Lymphoma: a European panel perspective. BMC Cancer. 2020;20(1):1088.

39. Moskowitz CH, Walewski J, Nademanee A, Masszi T, Agura E, Holowiecki J, et al. Five-year PFS from the AETHERA trial of brentuximab vedotin for
Hodgkin lymphoma at high risk of progression or relapse. Blood. 2018;132(25):2639-2642

40. Geoerger B, Kang HJ, Yalon-Oren M, Marshall LV, Vezina C, Pappo A, et al. Pembrolizumab in paediatric patients with advanced melanoma or a PD-L1-positive, advanced, relapsed, or refractory solid tumour or lymphoma (KEYNOTE-051): interim analysis of an open-label, single-arm, phase 1-2 trial. Lancet Oncol. 2020;21(1):121-133

41. Castanha L, Santoro A, Carlo-Stella C. Salvage Therapy for Hodgkin's Lymphoma: A Review of Current Regimens and Outcomes. Journal of Blood Medicine. 2020;11:389-403

42. Satwani $P$, Jin Z, Martin PL, Bhatia M, Garvin $\mathrm{JH}$, George $\mathrm{D}$, et al. Sequential myeloablative autologous stem cell transplantation and reduced intensity allogeneic hematopoietic cell transplantation is safe and feasible in children, adolescents and young adults with poor-risk refractory or recurrent Hodgkin and non-Hodgkin lymphoma. Leukemia. 2015;29(2):448-55

43. Castagna L, Bramanti S, Devillier R, Sarina B, Crocchiolo R, Furst $S$, et al. Haploidentical transplantation with post-infusion cyclophosphamide in advanced Hodgkin lymphoma. Bone Marrow Transplant. 2017;52(5):683-688.

44. Castagna L, Busca A, Bramanti S, Raiola Anna M, Malagola M, Ciceri F, et al. Haploidentical related donor compared to HLA-identical donor transplantation for chemosensitive Hodgkin lymphoma patients. BMC Cancer. 2020;20(1):1140

45. Mariotti J, Devillier R, Bramanti S, Sarina B, Furst S, Granata A, et al. T Cell-Replete Haploidentical Transplantation with Post-Transplantation Cyclophosphamide for Hodgkin Lymphoma Relapsed after Autologous Transplantation: Reduced Incidence of Relapse and of Chronic Graft-versus-Host Disease Compared with HLA-Identical Related Donors. Biol Blood Marrow Transplant. 2018;24(3):627-632

46. Gauthier J, Poiré X, Gac AC, Leclerc M, Guillaume T, Chalandon Y, et al. Better outcome with haploidentical over HLA-matched related donors in patients with Hodgkin's lymphoma undergoing allogeneic haematopoietic cell transplantation-a study by the Francophone Society of Bone Marrow Transplantation and Cellular Therapy. Bone Marrow Transplant. 2018;53(4):400-409 